\title{
Digital Forensics Domain and Metamodeling Development Approaches
}

\author{
Omair Ameerbakhsh \\ College of Computer Science and \\ Engineering. Information system \\ department. Taibah University. Saudi \\ Arabia. Madina \\ oameerbakhsh@taibahu.edu.sa \\ Amer Nizar Abu Ali \\ College of Computer Science and \\ Engineering. Information system \\ department. Taibah University. Saudi \\ Arabia. Madina \\ aabuali@taibahu.edu.sa
}

\author{
Fahad M Ghabban \\ College of Computer Science and \\ Engineering. Information system \\ department. Taibah University. \\ Saudi Arabia. Madina \\ fghaban@taibahu.edu.sa \\ Arafat Al-Dhaqm \\ School of Computing, \\ Faculty of Engineering \\ University Technology Malaysia \\ Malaysia, Johor \\ mrarafat1@utm.my
}

\author{
Ibrahim Alfadli \\ College of Computer Science and \\ Engineering. Information system \\ department. Taibah University. \\ Saudi Arabia. Madina \\ ialfadli@taibahu.edu.sa
}
Mahmoud Ahmad Al-Khasawneh Faculty of Computer \& Information Technology
Al-Madinah International University
Shah Alam, Malaysia
mahmoud@outlook.my

\begin{abstract}
Metamodeling is used as a general technique for integrating and defining models from different domains. This technique can be used in diverse application domains, especially for purposes of standardization. Also, this process mainly has a focus on the identification of general concepts that exist in various problem domain and their relations and to solve complexity, interoperability, and heterogeneity aspects of different domains. Several diverse metamodeling development approaches have been proposed in the literature to develop metamodels. Each metamodeling development process has some advantages and disadvantages too. Therefore, the objective of this paper is to provide a comprehensive review of existing metamodeling development approaches and conduct a comparative study among them-eventually selecting the best approach for metamodel development in the perspective of digital forensics.
\end{abstract}

Keywords - Digital forensics, Metamodel, Metamodeling

\section{INTRODUCTION}

Digital Forensics (DFs) domain is a diverse and a mbiguous domain. It has many overloading concepts, terminologies, processes, tasks, activities, subdomains, etc [1]-[6]. This diversity and ambiguity make it complex and unstruct ure d a mong domain forensic investigators[7]-[9]. For example, the database foren sics field has many subd omain s (e.g: ora cle database forensics, MSSQL server database forensics, MySQL database forensics, DB2 database forensic, PostgreSQL database forensics, and SQLite database forensics) which produced many and overloading forensics models and fra mework for database forensics field [10], [11]. Sim ila rly, mobile forensics, network forensics, IoT forensics, Drone's forensics, email forensics, and wireless forensics [1], [12][14]. This diversity makes the DFs field unorganized, ununified, unstructured, complex, heterogeneous, and ambiguous [9], [15]. Therefore, semantic metamodeling la nguage (high abstract model) is required to orga nize, un if y, and structure theDFs domain knowledge in one standardized model. For this purpose, the metamodeling approach is a proper method to develop a sematic metamodeling la nguage (metamodel) for the DFs domain. Metamodeling is used a s a general technique for integrating and defining models from different domains [16]. Common concepts of these different views can be identified and shared. The metamodeling technique consequently can be applied in quite different application domains, especially for standardization purposes. Metamodeling is simply the identification of general concepts that ex ist in ea ch problem domain and their rela tions. It is used to solve the complexity, interoperability, and heterogeneity of the domain [17], [18]. Metamodels should therefore be rigorously defined as well as being well-structured. The metamodel is a model about a model; it is the expla nation of the model. It can specif y concepts, attributes, operations, and associations to model a specific domain [19][20]. A metamodel is a precise definition of modeling elements (concepts, a ttributes, operations, and a ssociations, a nd rules) needed for creating semantic models [21]. Theseelements a re used to construct a domain model. Also, a metamodel is thus a prescriptive/description model of a modeling la nguage. It is used to solve the a mbiguity and heterogeneity of complex domains through the generation of solution models [9], [22 ], [23].

Therefore, the objective of this paper is to make a comparative analy sis a mong meta mo deling a pproaches to select the best one which may use for organizing and structuring the DFs domain. The results show that the

This paper is orga nized as follows: Section 1 introduce d a brief introduction about metamodeling approaches and DFs domain, the metamodeling development approaches are 
presented in Section 2. Section 3 provided a comparative a naly sis a mong metamodeling a pproaches, whereas Section 4 displayed the demonstration of the metamodeling a pproaches, and finally Section 5 summarized this paper.

\section{Metamodeling DeVElopment APPROACHES}

Metamodeling is used as a general technique for integrating a nd defining models from different domains [16]. Common concepts of these different views can be identified and shared. Mainly, this technique can be applied in quite different application domains, especially for standardization purposes. Metamodeling means the identification of ge neral concepts that ex ist in ea ch problem domain and their relations. It is used to solve the complexity, interoperability, and heterogeneity of the domain [17][18]. Metamodels should therefore be rigorously defined as well as being wellstructured. The metamodeldevelopment process is u sed to construct a metamodel, where the process of constructing a metamodel at the M2 level is termed 'metamodel development' [24]. Consequently, the metamodeling development process ensures that the outcome of a metamodel is complete and consistent [25]. Each me tamodel development process has advantages and disadvantages. For exa mple, Polynomial regression method PR [26], Finite sta te machine [27][28], AIMS [29], and Learning-by-doing Approach-Knowledge-based engineering [30] are more suitable for the simulation models. While Kriging [31], Specification-Driven Development of an Executable Metamodel in Eiffel [32]), Towards Automated Testing of Abstra ct Syntax Specifications of Domain-Specific Modelling Languages [33], Test-driven Approach-model de velopment [34], Metamodeling for Business Model Design [35], and Metamodeling Creation process [24]. Table I displays the comparison among existing metamodeling development approaches.

TABLE I. EXISTING METAMODELING APPROACHES

\begin{tabular}{|l|l|}
\hline \multicolumn{1}{|c|}{$\begin{array}{c}\text { Development } \\
\text { Process }\end{array}$} & \multicolumn{2}{c|}{ Description } \\
\hline $\begin{array}{l}\text { Adaptive and } \\
\text { Interactive } \\
\text { Modelling System } \\
\text { (AIMS) [29] }\end{array}$ & $\begin{array}{l}\text { AIMS is viewed as a learning activity and inductive } \\
\text { machine learning techniques from Artificial } \\
\text { Intelligence and combined with traditional optimization } \\
\text { methods to form a model building system. This } \\
\text { metamodeling process includes two steps: } \\
\text { 1. Competitive Relation Learner (CRL): } \\
\text { responsible for generating metamodels from } \\
\text { training examples. }\end{array}$ \\
& $\begin{array}{l}\text { Induction/Selection Optimizer (ISO): uses a } \\
\text { multiple-objective optimization method to } \\
\text { choose the relevant modeling strategies }\end{array}$ \\
\hline $\begin{array}{l}\text { Polynomial } \\
\text { Regression (PR) }\end{array}$ & $\begin{array}{l}\text { PR has been applied in designing complex engineering } \\
\text { [26stems. Originally this polynomial modeling method } \\
\text { was developed to produce smooth approximation } \\
\text { models of response data contaminated with random } \\
\text { found in the typical physical (stochastic) }\end{array}$ \\
& $\begin{array}{l}\text { experiment. It includes two steps: } \\
\text { Recognize the centrality of diverse outlines } \\
\text { considers straightforwardly from the } \\
\text { coefficients in the standardized relapse }\end{array}$ \\
\hline
\end{tabular}

\begin{tabular}{|c|c|}
\hline & $\begin{array}{l}\text { model. For issues with an extensive } \\
\text { measurement, it is essential to utilize } \\
\text { straight or second-request polynomial } \\
\text { models to limit the outline variables to the } \\
\text { most basic ones. } \\
\text { 2. Optimization, the smooth ability of } \\
\text { polynomial regression permits a speedy } \\
\text { meeting of boisterous capacities. }\end{array}$ \\
\hline $\begin{array}{l}\text { Blind Kriging- } \\
\text { engineering design } \\
{[31]}\end{array}$ & $\begin{array}{l}\text { This process aims to define a metamodel for corporate } \\
\text { real estate management it has so far been mainly based } \\
\text { on more static approaches such as balanced scorecard, } \\
\text { resulting in rather static management models and } \\
\text { principles that are needed but inadequate to reflect the } \\
\text { dynamic, agile, networked environment of today. It } \\
\text { consists of four steps: } \\
\text { 1. Background review on the topic also on } \\
\text { related fields. } \\
\text { 3. Search for and assemble related studies. } \\
\text { 4. Builds a framework with the data separated. }\end{array}$ \\
\hline $\begin{array}{l}\text { Specification- } \\
\text { Driven } \\
\text { Development of an } \\
\text { Executable } \\
\text { Metamodel in } \\
\text { Eiffel [32] }\end{array}$ & $\begin{array}{l}\text { The authors combined specifications and tests to guide } \\
\text { the construction of Eiffel metamodels. Specifications } \\
\text { are given as Eiffel contracts, whereas tests are written } \\
\text { using the acceptance test framework for Eiffel. It } \\
\text { consists of five steps: } \\
\text { 1. A brief modeling phase, where determined } \\
\text { the classes that were needed for } \\
\text { representing the metamodel. } \\
\text { 2. Sketch of parts of these class diagrams } \\
\text { 3. Determine a preliminary set of Eiffel } \\
\text { classes. } \\
\text { 4. Capture a set of well-formed rules in the } \\
\text { 5. Apply validation and transformation. }\end{array}$ \\
\hline $\begin{array}{l}\text { Learning-by-doing } \\
\text { approach- } \\
\text { Knowledge-based } \\
\text { engineering [30] }\end{array}$ & $\begin{array}{l}\text { Garcia has developed a technology approach that relies } \\
\text { on the integration of an object-oriented programming } \\
\text { environment and a geometric modeler. The technology } \\
\text { has been intensively used by large aerospace and } \\
\text { automotive companies to automate repetitive and } \\
\text { slightly variant engineering design tasks, thus } \\
\text { providing significant results in the design time } \\
\text { reduction. It consists of four steps: } \\
\text { 1. Investigation of the information codes. } \\
\text { 2. Analysis of general code structure to } \\
\text { characterize a bound together deterioration } \\
\text { Schema. Analysis of the individual learning code } \\
\text { items is utilized to characterize the elements } \\
\text { in the operation metamodel. } \\
\text { 4. Investigate the legitimacy of the model. }\end{array}$ \\
\hline $\begin{array}{l}\text { Towards } \\
\text { Automated Testing } \\
\text { of Abstract Syntax } \\
\text { Specifications of } \\
\text { Domain-Specific } \\
\text { Modeling } \\
\text { Languages [33] }\end{array}$ & $\begin{array}{l}\text { This approach is used to support the specification of } \\
\text { positive and negative example models from which test } \\
\text { models for meta-model testing are generated. The } \\
\text { author is especially concerned with the testing of } \\
\text { metamodels. }\end{array}$ \\
\hline $\begin{array}{lr}\text { Finite } & \text { State } \\
\text { Machine } \quad(F S M)- \\
\text { Model-based } \\
\text { development [27] }\end{array}$ & $\begin{array}{l}\text { A semantic framework based on Abstract State } \\
\text { Machines (ASM) has been offered, which also includes } \\
\text { three translational semantics techniques: semantic } \\
\text { mapping, semantic hooking, and semantic meta- } \\
\text { hooking. However, the author does not demonstrate any } \\
\text { tool generation from their semantics specifications. } \\
\text { This process consists of: } \\
\text { 1. Reveals the modeling components for } \\
\text { indicating a model of conduct made from a }\end{array}$ \\
\hline
\end{tabular}




\begin{tabular}{|c|c|}
\hline & $\begin{array}{l}\text { limited number of states, moves between } \\
\text { those states, and occasions. } \\
\text { 2. Creates an "output event" based on its } \\
\text { present state and info. One of the states is } \\
\text { picked as an underlying state. The depiction } \\
\text { of both "deterministic and non- } \\
\text { deterministic" (for every pair of state and } \\
\text { info occasion there might be a few } \\
\text { conceivable next states) FSMs. }\end{array}$ \\
\hline $\begin{array}{l}\text { Test-driven } \\
\text { Approach-model } \\
\text { development [34] }\end{array}$ & $\begin{array}{l}\text { The authors assigned test cases to the MetaClasses in a } \\
\text { meta-model. Test cases are executable models written } \\
\text { in PHP and perform transformation like code } \\
\text { generation. If a test case shows that a meta-model is } \\
\text { inadequate, this must be manually modified. It consists } \\
\text { of six steps: } \\
\text { 1. Recognize domain concepts and their } \\
\text { 2. Improve the metamodel. } \\
\text { 3. Compose - a test model. } \\
\text { 4. Execute - the test model. } \\
\text { 5. Assess (casual) - if success goes to (2) if } \\
\text { 6. Recogo to (6). } \\
\text { 6. Recolize refactoring (casual). }\end{array}$ \\
\hline $\begin{array}{l}\text { Metamodeling for } \\
\text { Business Model } \\
\text { Design [35] }\end{array}$ & $\begin{array}{l}\text { Metamodeling process offered by Hauksson and } \\
\text { Johannesson to develop artifact for Business Model } \\
\text { Canvas. It consists of } 5 \text { steps: } \\
\text { 1. Explicate problem. } \\
\text { 2. Outline artifact and define requirements. } \\
\text { 3. Design and develop artifact. } \\
\text { 4. Demonstration } \\
\text { 5. Evaluation }\end{array}$ \\
\hline $\begin{array}{l}\text { Metamodeling } \\
\text { Creation Process } \\
{[24]}\end{array}$ & $\begin{array}{l}\text { Othman et al., provided metamodeling process creation } \\
\text { to develop and validate a domain model for domain } \\
\text { knowledge. It consists of } 8 \text { steps: } \\
\text { 1. Models' collection and preliminary domain } \\
\text { 2. } \text { study. } \\
\text { Identifying subsets of models to suit } \\
\text { 3. Exearch tasks. } \\
\text { 4. Short-lion of general concepts. } \\
\text { 5. Reconciliation of definitions. } \\
\text { 6. Designation of concepts. } \\
\text { 7. Identification of relationships. } \\
\text { 8. Validating the metamodel. }\end{array}$ \\
\hline
\end{tabular}

\section{COMPARATIVE ANALSYSIS}

The comparison among meta modeling a pproaches shows clearly that [24] approach is more suitable for modelling a ny complex knowledge domain because it is the most recent and also covered whole existing development process steps in other metamodeling process a pproaches (e.g.: identify domain source, extractdomain concepts, filtering domain concepts, reviewing domain concepts, merging domain concepts, identify domain concepts relationships, design metamodel, validate metamodel, and enhance metamodel). Also, it has a $n$ additional step that requires the researcher to select the most suitable domain model by using coverage measure, a swell a s a validation step to ensure the correctness and completeness of the metamodel developed. Figure 1 displays the metamodeling development process proposed by [24].

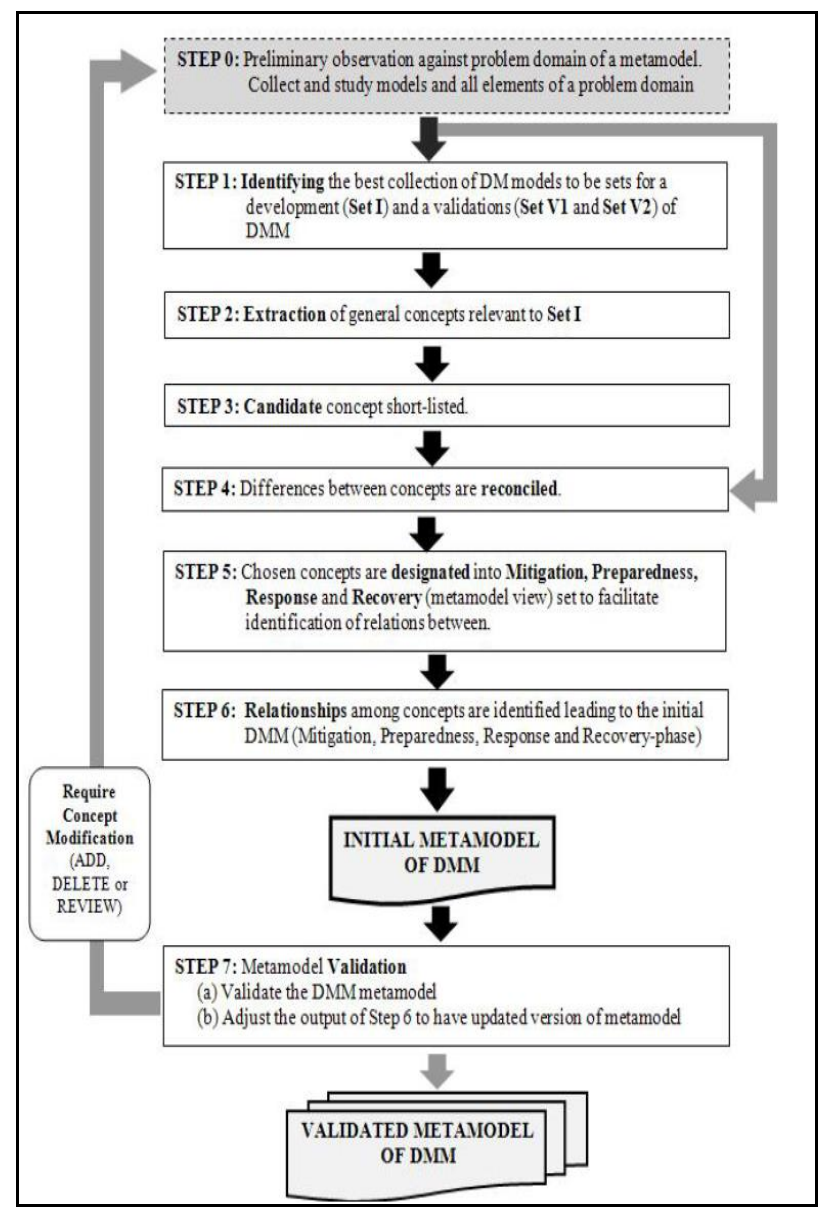

Fig. 1. Metamodeling development approach [24]

\section{ORGANIZED AND STRUCTURED DIGITAL FORENSICS DOMAIN USING METAMODELING APPROACH}

This section takes a DFs domain as a case study of the complex and heterogeneous domains. As mentioned in Section I, several and overlapping studies exists in literature that is focused in DFs domain. For example, the database foren sic s field received many works from different authors to deal with different database incidents[36] [37] [3], [10], [11], [38]-[46]. However, it lacks the high abstract model. Mobile forensics field received several works to solve mobile inciden ts [47][50]. IoT forensics received several works[51] [52]-[61]. Similarly, several studies [12], [13], [62]-[64] have ex plored Network forensics-related works. A closely rela ted subdomain of network forensics, cloud forensics, has also received significa nt research works [1], [8], [53], [65]. Through this of DFs domain, the metamodeling approach is essential for purposes of developing sematic metamodeling la nguage as shown in Figure 2. The M2-Digital forensic metamodel is the highest level of the DFs metamodel which represents the common DFs concepts, M1-Digital foren sic models represent the second level/layer of the is DFs metamodel, which governed by M2 level. M0-Digital forensic real models a re an instance on the M1-Digital forensic metamodel. 


\section{Conclusion}

This paper reviewed and compared several metamodeling a pproaches used to structure and organize heterogeneou s and complex domains. The best metamodeling approaches have been identified to structure and organize he terogeneity and ambiguity domains. The DFs domain is discussed in this paper as a case study of the heterogenous and complex. domain. Also, this study, suggests developing a semantic metamodeling language for the DFs domain to facilitate, organize, unify, and ruse it a mong domain users. The fu ture work of this paper is to develop and validate the DFs metamodel using the metamodeling a pproach.

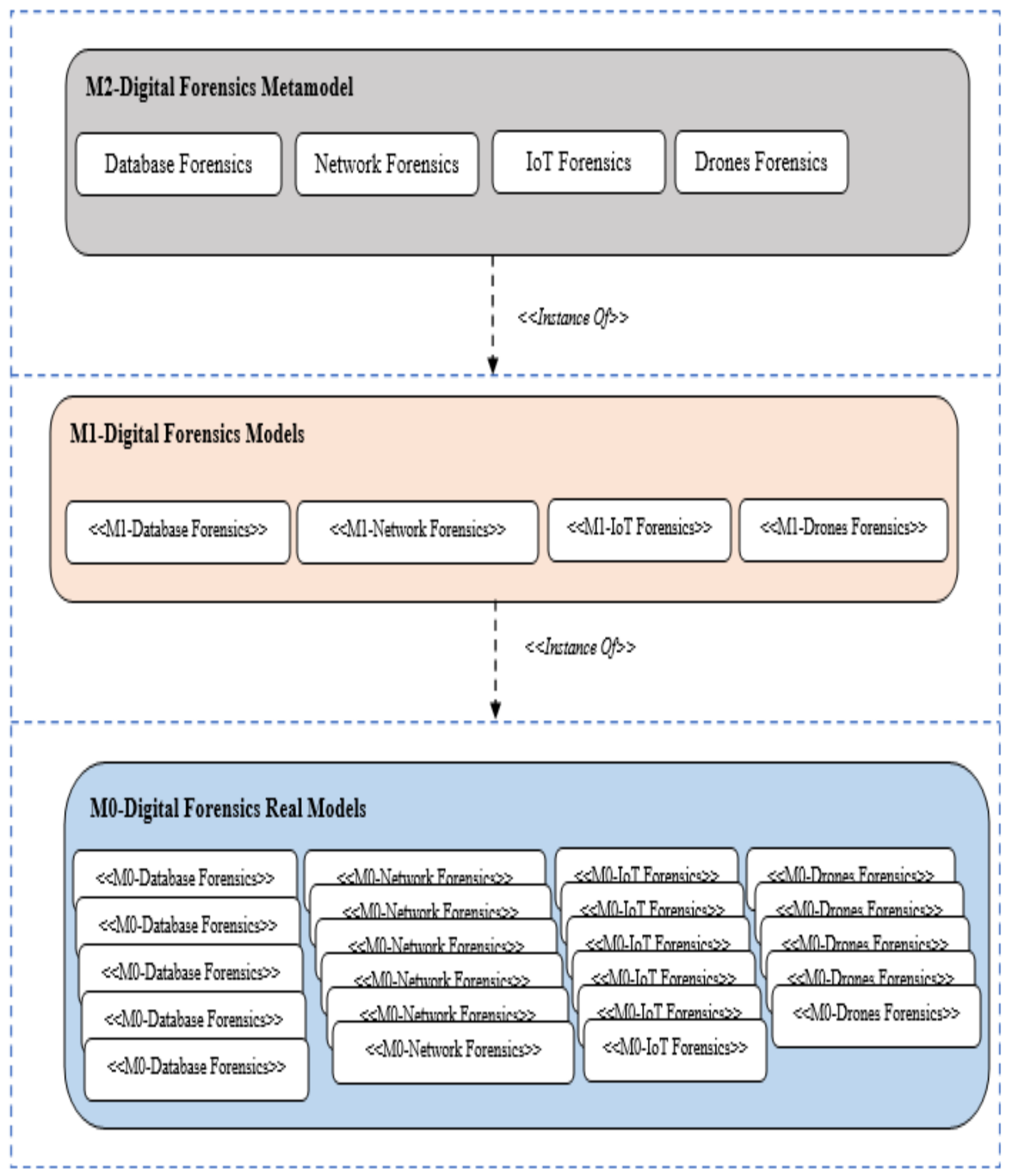

Fig. 2. Semantic metamodeling language for DFs domain 


\section{REFERENCES}

[1] V. R. Kebande and H. S. Venter, "On digital forensic readiness in the cloud using a distributed agent-based solution: issues and challenges," Aust. J. Forensic Sci., vol. 50, no. 2, 2018, doi: 10.1080/00450618.2016.1194473.

[2] V. R. Kebande, N. M. Karie, R. A. Ikuesan, and H. S. Venter, "Ontology-driven perspective of CFRaaS," Wiley Interdiscip. Rev. Forensic Sci., p. e1372.

[3] A. Al-Dhaqm, S. Razak, R. A. Ikuesan, V. R Kebande, and S. Hajar Othman, "Face Validation of Database Forensic Investigation Metamodel," Infrastructures, vol. 6, no. 2, p. 13, 2021.

[4] D. Ellison, A. R. Ikuesan, and H. Venter, "Description Logics and Axiom Formation for a Digital Forensics Ontology," in European Conference on Cyber Warfare and Security, 2019, pp. 742--XIII.

[5] D. Ellison, H. Venter, and A. Ikuesan, "An Improved Ontology for Knowledge Management in Security and Digital Forensics," in European Conference on Cyber Warfare and Security, 2017, pp. 725--733.

[6] D. Ellison, R. A. Ikuesan, and H. S. Venter, "Ontology for Reactive Techniques in Digital Forensics," 2019 IEEE Conf. Appl. Inf. Netw. Secur. AINS 2019, pp. 83-88, 2019, doi:

10.1109/AINS47559.2019.8968696

[7] R. A. Ikuesan, "Online Psychographic Model for Insider Identification," Universiti Teknologi Malaysia, 2016.

[8] V. R. Kebande and H. S. Venter, "A cloud forensic readiness model using a Botnet as a Service," in The international conference on digital security and forensics (DigitalSec2014), 2014, pp. 23-32.

[9] N. M. Karie, V. R. Kebande, H. S. Venter, and K. R. Choo, "On the importance of standardising the process of generating digital forensic reports," Forensic Sci. Int. Reports, 2019, doi: 10.1016/j. fsir. 2019.100008.

[10] A. Al-Dhaqm, S. Razak, K. Siddique, R. A. Ikuesan, and V. R. Kebande, "Towards the Development of an Integrated Incident Response Model for Database Forensic Investigation Field," IEEE Access, 2020.

[11] A. Al-Dhaqm et al., "Categorization and Organization of Database Forensic Investigation Processes," IEEE Access, vol. 8, pp. 112846 112858, 2020, doi: 10.1109/access.2020.3000747.

[12] I. R. Adeyemi, S. Abd Razak, and N. A. N. Azhan, "A review of current research in network forensic analysis," Int. J. Digit. Crime Forensics, vol. 5, no. 1, pp. 1-26, 2013.

[13] S. Pretorius, A. R. Ikuesan, and H. S. Venter, "Attributing users based on web browser history," in 2017 IEEE Conference on Applications, Information and Network Security, AINS 2017, 2018 vol. 2018-Janua, doi: 10.1109/AINS.2017.8270427.

[14] V. R. Kebande and N. M. Karie, "A Framework for Integrating Multimodal Biometrics with Digital Forensics,"vol. 4, no. November 2015, pp. 498-507, 2016, doi: 10.17781/P001929.

[15] S. O. Baror, H. S. Venter, and R. Adeyemi, "A natural human language framework for digital forensic readiness in the public cloud," Aust. J. Forensic Sci., vol. 0, no. 0, pp. 1-26, 2020, doi: 10.1080/00450618.2020.1789742.

[16] R. Geisler, M. Klar, and C. Pons, "Dimensions and dichotomy in metamodeling," in 3rd BCS-FACS Northern Formal Methods Workshop 3, 1998, pp. 1-20.

[17] J. Whittle, "Workshops and Tutorials at the UML 2002 Conference," in International Conference on the Unified Modeling Language, 2002, pp. 442-447.

[18] N. M. Karie, "Building Ontologies for Digital Forensic Terminologies," Int. J. Cyber-Security Digit. Forensics, vol. 5, no. 2, pp. 75-82, 2016, doi: 10.17781/p002032.

[19] J. Bézivin and O. Gerbé, "Towards a precise definition of the OMG/MDA framework," in Proceedings 16th Annual International Conference on Automated Software Engineering (ASE 2001), 2001, pp. 273-280.

[20] V. R. Kebande, N. M. Karie, A. Michael, S. M. G. Malapane, and H. S. Venter, "How an IoT-enabled 'smart refrigerator' can play a clandestine role in perpetuating cyber-crime," 2017, doi: 10.23919/ISTAFRICA.2017.8102362.
[21] N. Koch and A. Kraus, "Towards a common metamodel for the development of web applications," in International Conference on Web Engineering, 2003, pp. 497-506.

[22] U. Aßmann, S. Zschaler, and G. Wagner, "Ontologies, meta-models, and the model-driven paradigm," in Ontologies for software engineering and software technology, Springer, 2006, pp. 249-273.

[23] V. R. Kebande, N. M. Karie, and H. S. Venter, "A generic Digital Forensic Readiness model for BYOD using honeypot technology," 2016 IST-Africa Conf. IST-Africa 2016, pp. 1-12, 2016, doi: 10.1109/ISTAFRICA.2016.7530590

[24] S. H. Othman, G. Beydoun, and V. Sugumaran, "Development and validation of a Disaster Management Metamodel (DMM)," Inf. Process. Manag., vol. 50, no. 2, pp. 235-271, 2014.

[25] A. Abdullah, S. H. Othman, and M. N. Razali, "Structuring knowledge on house Price Volatility through a metamodel," 2006.

[26] W. C. Engelund, D. O. Stanley, R. A. Lepsch, M. M. McMillin, and R. Unal, "Aerodynamic configuration design using response surface methodology analysis," NASA STI/Recon Tech. Rep. A, vol. 94, p. 10718, 1993.

[27] A. Gargantini, E. Riccobene, and P. Scandurra, "A semantic framework for metamodel-based languages," Autom. Softw. Eng., vol. 16, no. 3, pp. 415-454, 2009.

[28] V. Kebande and H. S. Venter, "A functional architecture for cloud forensic readiness large-scale potential digital evidence analysis," in European Conference on Information Warfare and Security, ECCWS, 2015, vol. 2015-Janua.

[29] S.-Y. Lu and D. K. Tcheng, "Building layered models to support engineering decision making: A machine learning approach," 1991. P. Bermell-Garcia, "A metamodel to annotate knowledge based engineering codes as enterprise knowledge resources," 2007.

[31] W. E. Biles, J. P. C. Kleijnen, W. C. M. Van Beers, and I. Van Nieuwenhuyse, "Kriging metamodeling in constrained simulation optimization: an explorative study," in 2007 Winter Simulation Conference, 2007, pp. 355-362.

[32] R. F. Paige, P. J. Brooke, and J. S. Ostroff, "Specification-driven development of an executable metamodel in Eiffel," WISME'04, 2004

[33] D. A. Sadilek and S. Weißleder, "Towards Automated Testing of Abstract Syntax Specifications of Domain-Specific Modeling Languages.," in DSML, 2008, pp. 21-29.

[34] A. Cicchetti, D. Di Ruscio, A. Pierantonio, and D. S. Kolovos, "A test-driven approach for metamodel development," in Emerging Technologies for the Evolution and Maintenance of Software Models, IGI Global, 2012, pp. 319-342.

[35] H. Hauksson, "Metamodeling for Business Model Design: Facilitating development and communication of Business Model Canvas (BMC) models with an OMG standards-based metamodel.” 2013.

[36] V. R. Kebande, N. M. Karie, and H. S. Venter, "Cloud-Centric Framework for isolating Big data as forensic evidence from IoT infrastructures," in 2017 1st International Conference on Next Generation Computing Applications (NextComp), 2017, pp. 54-60.

[37] V. R. Kebande, "A Novel Cloud Forensic Readiness Service Model by," p. 298, 2017.

[38] A. Al-Dhaqm et al., "Database forensic investigation process models: A review," IEEE Access, vol. 8, pp. 48477-48490, 2020, doi: 10.1109/ACCESS.2020.2976885.

[39] A. Aldhaqm, S. Abd Razak, and S. H. Othman, "Common Investigation Process Model for Database Forensic Investiga-tion Discipline."

[40] A. Al-Dhaqm et al., "CDBFIP: Common database forensic investigation processes for Internet of Things," IEEE Access, vol. 5, pp. 24401-24416, 2017.

[41] A. Al-Dhaqm, S. Razak, S. H. Othman, A. Ngadi, M. N. Ahmed, and A. A. Mohammed, Development and validation of a database forensic metamodel (DBFM), vol. 12, no. 2. 2017.

[42] A. M. R. Al-Dhaqm, S. H. Othman, S. Abd Razak, and A. Ngadi, "Towards adapting metamodelling technique for database forensics investigation domain," in 2014 International Symposium on Biometrics and Security Technologies (ISBAST), 2014, pp. 322-327. [43] A. Al-Dhaqm, S. A. Razak, S. H. Othman, A. Nagdi, and A. Ali, "A 
generic database forensic investigation process model," J. Teknol. vol. 78, no. 6-11, 2016, doi: $10.11113 /$ jt.v78.9190.

[44] A. Aldhaqm, S. Abd Razak, S. H. Othman, A. Ali, and A. Ngadi, "Conceptual investigation process model for managing database forensic investigation knowledge," Res. J. Appl. Sci. Eng. Technol., vol. 12, no. 4, pp. 386-394, 2016.

[45] M. Ngadi, R. Al-Dhaqm, and A. Mohammed, "Detection and prevention of malicious activities on RDBMS relational database management systems," Int. J. Sci. Eng. Res., vol. 3, no. 9, pp. 1-10, 2012.

[46] A. Al-Dhaqm, S. Razak, and S. H. Othman, "Model derivation system to manage database forensic investigation domain knowledge," in 2018 IEEE Conference on Application, Information and Network Security (AINS), 2018, pp. 75-80.

[47] A. Ali, S. Abd Razak, S. H. Othman, A. Mohammed, and F. Saeed, A Metamodel for Mobile Forensics Investigation Domain, vol. 12, no. 4. 2017.

[48] A. Ali, S. A. Razak, S. H. Othman, and A. Mohammed, "Towards adapting metamodeling approach for the mobile forensics investigation domain," in International Conference on Innovation in Science and Technology (IICIST), 2015, p. 5.

[49] A. Ali, S. Abd Razak, S. H. Othman, and A. Mohammed, "Extraction of common concepts for the mobile forensics domain," in International Conference of Reliable Information and Communication Technology, 2017, pp. 141-154.

[50] A. Al-Dhaqm, S. Abd Razak, R. A. Ikuesan, V. R. Kebande, and K. Siddique, "A Review of Mobile Forensic Investigation Process Models,"IEEE Access, vol. 8, pp. 173359-173375, 2020.

[51] V. R. Kebande, N. M. Karie, R. D. Wario, and H. S. Venter, "Forensic profiling of cyber-security adversaries based on incident similarity measures interaction index," 2019, doi: 10.1109/ICONIC.2018.8601279.

[52] V. R. Kebande, N. M. Karie, A. Michael, S. M. G. Malapane, and H. S. Venter, "How an IoT-enabled 'smart refrigerator' can play a clandestine role in perpetuating cyber-crime," 2017 IST-Africa Week Conf. IST-Africa 2017, pp. 1-10, 2017, doi: 10.23919/ISTAFRICA.2017.8102362.

[53] S. M. Makura, H. S. Venter, R. A. Ikuesan, V. R. Kebande, and N. M. Karie, "Proactive Forensics: Keystroke Logging from the Cloud as Potential Digital Evidence for Forensic Readiness Purposes," in 2020 IEEE International Conference on Informatics, IoT, and Enabling Technologies (ICIoT), 2020, pp. 200-205.

[54] S. Khorashadizadeh, A. R. Ikuesan, and V. R. Kebande, "Generic 5g infrastructure for iot ecosystem," in Advances in Intelligent Systems and Computing, 2020, vol. 1073, pp. 451-462, doi: 10.1007/978-3030-33582-3_43.

[55] V. R. Kebande, N. M. Karie, and H. S. Venter, "Adding digital forensic readiness as a security component to the IoT domain," 2018.

[56] V. R. Kebande et al., "Towards an integrated digital forensic investigation framework for an IoT-based ecosystem," in 2018 IEEE International Conference on Smart Internet of Things (SmartIoT), 2018, pp. 93-98.

[57] V. R. Kebande, R. A. Ikuesan, N. M. Karie, S. Alawadi, K.-K. R. Choo, and A. Al-Dhaqm, "Quantifying the need for supervised machine learning in conducting live forensic analysis of emergent configurations (ECO) in IoT environments," Forensic Sci. Int. Reports, vol. 2, p. 100122, 2020.

[58] V. R. Kebande and H. S. Venter, "A comparative analysis of digital forensic readiness models using CFRaaS as a baseline," Wiley Interdiscip. Rev. Forensic Sci., vol. 1, no. 6, p. e1350, 2019.

[59] V. R. Kebande and I. Ray, "A generic digital forensic investigation framework for internet of things (iot)," in 2016 IEEE 4th International Conference on Future Internet of Things and Cloud (FiCloud), 2016, pp. 356-362.

[60] V. R. Kebande, P. P. Mudau, R. A. Ikuesan, H. S. Venter, and K.-K. R. Choo, "Holistic digital forensic readiness framework for IoTenabled organizations," Forensic Sci. Int. Reports, vol. 2, p. 100117, 2020.

[61] V. R. Kebande and R. A. Ikuesan, "Virtual sensor forensics," 2020, doi: $10.1145 / 3415088.3415117$

[62] A. R. Ikuesan and H. S. Venter, "Digital behavioral-fingerprint for user attribution in digital forensics: Are we there yet?,"Digit. Investig., vol. 30, pp. 73-89, 2019, doi: 10.1016/j.diin.2019.07.003.

[63] A. Singh, A. R. Ikuesan, and H. S. Venter, "Digital Forensic Readiness Framework for Ransomware Investigation," in Lecture Notes of the Institute for Computer Sciences, Social-Informatics and Telecommunications Engineering, LNICST, 2019, vol. 259, pp. 91105, doi: 10.1007/978-3-030-05487-8_5.

[64] I. R. Adeyemi, S. A. Razak, M. Salleh, and H. S. Venter, "Leveraging human thinking style for user attribution in digital forensic process," Int. J. Adv. Sci. Eng. Inf. Technol., vol. 7, no. 1, pp. 198-206, 2017, doi: 10.18517/ijaseit.7.1.1383.

[65] N. M. Karie, V. R. Kebande, R. A. Ikuesan, M. Sookhak, and H. S. Venter, "Hardening SAML by Integrating SSO and Multi-Factor Authentication (MFA) in the Cloud," in ACM International Conference Proceeding Series, 2020, p. In Press, doi: $10.1145 / 3386723.3387875$. 